\title{
Production of 6-Deoxy-13-cyclopropyl-Erythromycin B by Saccharopolyspora erythraea
}

\author{
NRRL 18643
}

\author{
Maria S. Brown*, John P. Dirlam, Hamish A. I. Mcarthur, Ellen L. McCormick, \\ Brook K. Morse, Paul A. Murphy, Thomas N. O’Connell, Mike Pacey ${ }^{\dagger}$, \\ DiANNE M. RESCEK, JOHN RUDDOCK ${ }^{\dagger}$ and RICHARD G. WAX \\ Pfizer Central Research, \\ Eastern Point Road, Groton, CT 06340 USA \\ ${ }^{\dagger}$ Animal Health Central Research, Pfizer Central Research, \\ Ramsgate Road, Sandwich Kent, CT13 9NJ, England \\ (Received for publication April 16, 1999)
}

\begin{abstract}
Cyclopropane carboxylic acid was fed to Saccharopolyspora erythraea NRRL 18643 (6deoxyerythromycin producer), resulting in the production of 6-deoxy-13-cyclopropyl-erythromycin B. These studies provide further evidence that deoxyerythronolide B synthase has a relaxed specificity for the starter unit.
\end{abstract}

The biosynthesis of the erythromycin aglycone, 6-deoxyerythronolide B (1), is carried out by deoxyerythronolide $B$ synthase (DEBS), a type I modular polyketide synthase (PKS), in a manner analogous to fatty acid synthesis (Figure 1). This aglycone is derived from a propionyl-CoA starter unit and six (2S)-methylmalonyl-CoA extender units". The chain is subsequently cleaved from the PKS and cyclized to form 1. Previous work using a cell free system has shown that the first two modules of DEBS have a relaxed specificity for the starter unit ${ }^{2}$. Using this in vitro system, novel triketide lactones were formed by the incorporation of alternate starter units, acetyl-CoA and butyrylCoA. Saccharopolyspora erythraea has also been shown to be capable of acetate incorporation in vivo to form 15-norerythromycin $\mathrm{C}$ and 8,8a-deoxyoleandolide ${ }^{3,4)}$. Recent results demonstrated that the wild type strain, S. erythraea NRRL 2338, can incorporate cyclopropane carboxylic acid and cyclobutane carboxylic acid to form novel erythromycins ${ }^{5)}$. Based on these data, it was hypothesized that novel forms of 6-deoxy-erythromycin could be produced by feeding cyclopropane carboxylic acid to $S$. erythraea NRRL 18643, a genetically-engineered strain with a knockout in the C-6 hydroxylase (ery F $)^{6}$. This hypothesis was demonstrated experimentally.

\section{Materials and Methods}

Microorganism

Saccharopolyspora erythraea NRRL 18643 was maintained as a $20 \%$ glycerol stock at $-20^{\circ} \mathrm{C}$.

Production of 6-Deoxy-13-cyclopropyl-erythromycin B at Flask Scale

S. erythraea NRRL 18643 was plated onto 1/2YPD agar (Difco yeast extract $0.5 \%$, Difco Bacto peptone $0.5 \%$, dextrose $0.25 \%$, MOPS buffer $0.5 \%$, Difco Bacto agar $1.7 \%$, $\mathrm{pH}$ adjusted to 7.0 prior to autoclaving) and incubated at $28^{\circ} \mathrm{C}$ until grown (approximately 4 days). An agar plug (6 $\mathrm{mm}$ diameter) was used to inoculate a $250 \mathrm{ml}$ flask containing $25 \mathrm{ml}$ of $1 / 2$ YPD broth (Difco yeast extract $0.5 \%$, Difco Bacto peptone $0.5 \%$, dextrose $0.25 \%$, MOPS buffer $0.5 \%$, $\mathrm{pH}$ adjusted to 7.0 prior to autoclaving). The culture was incubated on a rotary shaker at $29^{\circ} \mathrm{C}, 225 \mathrm{rpm}$ for 24 hours. At this time, $2.5 \mathrm{ml}$ of the first stage culture was inoculated into a $250 \mathrm{ml}$ flask containing $25 \mathrm{ml}$ of Ery-P medium (dextrose $5 \%$, Nutrisoy flour $3 \%,\left(\mathrm{NH}_{4}\right)_{2} \mathrm{SO}_{4} 0.3 \%, \mathrm{NaCl} 0.5 \%$, $\mathrm{CaCO}_{3} 0.6 \%, \mathrm{pH}$ adjusted to 7.0 prior to autoclaving) which was then incubated as above for a total of six days. Cyclopropane carboxylic acid was added to the flasks at 24 and 48 hours to a final concentration of 200 ppm at each ad- 
Fig. 1a. The erythromycin PKS.
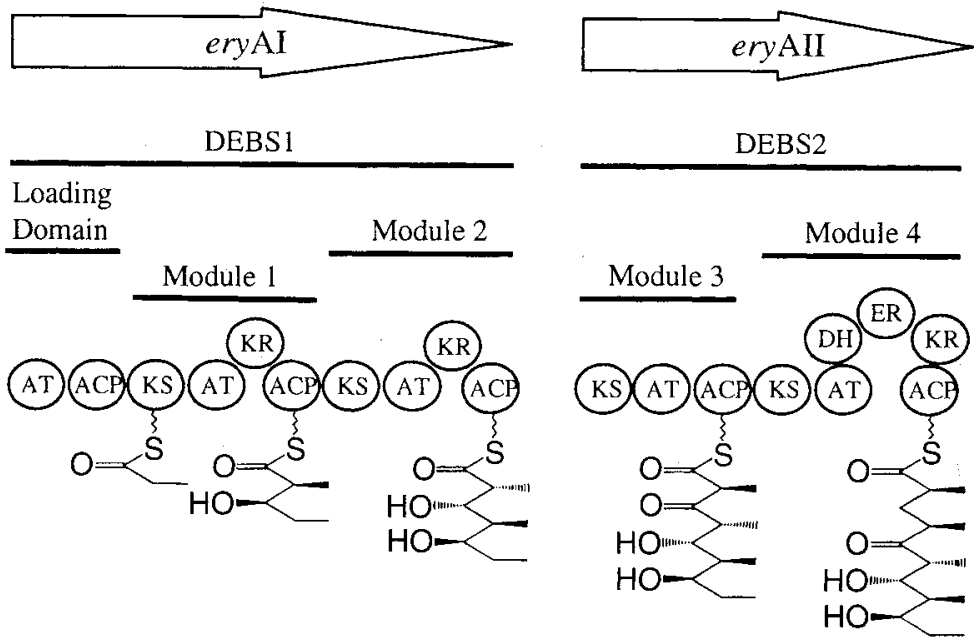
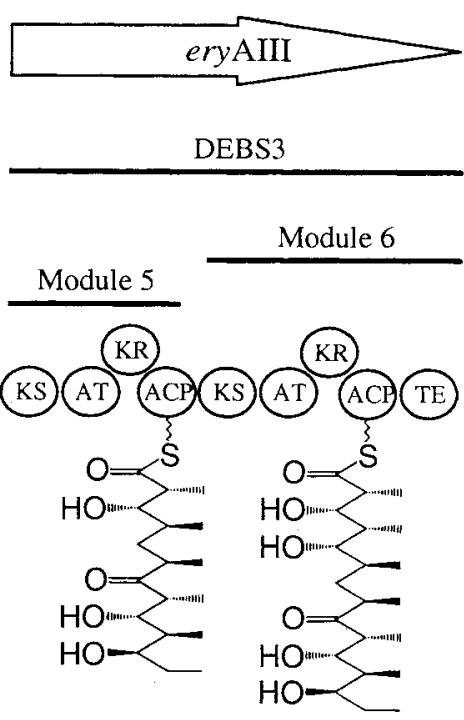

Adapted with permission from DONADIO et al. copyright 1991, American Association for the Advancement of Science ${ }^{7)}$.

Fig. 1b. Structures of 6-deoxyerythronolide B (1), erythromycin B (2) and erythromycin A (3).

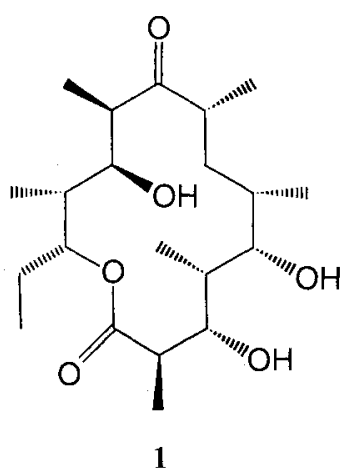

1

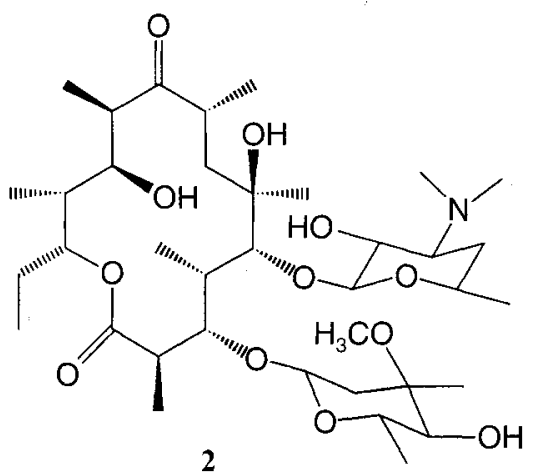

2

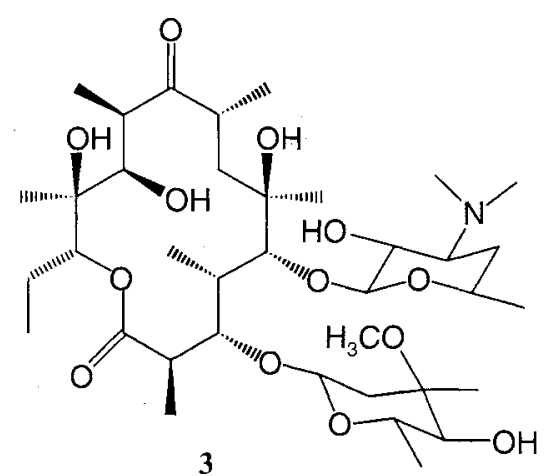

dition. After six days, whole broth was adjusted to $\mathrm{pH} 9.0$ with $\mathrm{NaOH}$. The fermentation was then extracted once with an equal volume of ethyl acetate. The organic phase was reduced to dryness under nitrogen $\left(45^{\circ} \mathrm{C}\right.$ bath). The residue was resuspended in $1.0 \mathrm{ml}$ methanol for HPLC-MS analysis. A novel peak was detected at 21.5 minutes by HPLCMS.

\section{Scaleup Procedure}

Four milliliters of NRRL 18643 were inoculated into 1 liter of TW medium (cerelose $0.5 \%$, tryptone $0.5 \%$, Difco yeast extract $0.25 \%$, EDTA $0.0036 \%$, pH adjusted to 7.1 prior to autoclaving) in a 2.8 liter fernbach flask and incubated on a rotary shaker at $29^{\circ} \mathrm{C}, 210 \mathrm{rpm}$ for 3 days. Cyclopropane carboxylic acid was added to this culture at 24 hours for a final concentration of $200 \mathrm{ppm}$. Eight hundred milliliters of this first stage were inoculated into a 14 liter fermentor (New Brunswick) containing 8 liters of modified Ery-P medium (prepared in 7 liters of water: cerelose 1\%, Nutrisoy flour $3 \%,\left(\mathrm{NH}_{4}\right)_{2} \mathrm{SO}_{4} 0.3 \%, \mathrm{NaCl} 0.5 \%, \mathrm{CaCO}_{3}$ 
$0.6 \%, \mathrm{MgSO}_{4} 0.05 \%$, corn steep solids $0.5 \%$, pH adjusted to 7.0 , autoclaved at $121^{\circ} \mathrm{C}, 99$ minutes; 1 liter of a $5 \%$ dextrose solution was autoclaved separately at $121^{\circ} \mathrm{C}, 30$ minutes then aseptically added to the fermentor for a final volume of 8 liters). The fermentor was run at $28^{\circ} \mathrm{C}, 8$ liters air/minute, $800 \mathrm{rpm}$, with $\mathrm{pH}$ controlled between 6.9 and 7.3 for 163 hours.

\section{Isolation}

After 163 hours, 16 liters of whole broth from two fermentors was adjusted to $\mathrm{pH} 9.0$ using $\mathrm{NaOH}$. Broth was then extracted with an equal volume of ethyl acetate. The organic phase was concentrated using a rotary evaporator, then dissolved in $500 \mathrm{ml}$ methylene chloride and extracted with an equal volume of $\mathrm{pH} 9.0$ water. The methylene chloride phase was dried in vacuo, yielding 10 grams of an oil. Nine grams of this material was dissolved in $50 \mathrm{ml}$ of dichloromethane and loaded onto a Biotage flash $40 \mathrm{M}$ prep system equipped with a silica cartridge. The column was sequentially eluted with $500 \mathrm{ml}$ of each of the following solvents: dichloromethane, dichloromethane-methanol (99:1), dichloromethane-methanol (90:10), dichloromethane - methanol - ammonia $(80: 20: 0.2)$, and methanol. Each mobile phase combination was collected as a single fraction $(500 \mathrm{ml})$. All macrolides eluted in the fraction corresponding to dichloromethane-methanol-ammonia $(80: 20: 0.2)$, yielding $522 \mathrm{mg}$ dry solid. This material was further purified by normal phase HPLC using a $5 \mu \mathrm{m}$ YMC diol column $(20 \times 250 \mathrm{~mm})$ with a mobile phase gradient of A - B $100: 0$ to $80: 20$ over 60 minutes at $20 \mathrm{ml} / \mathrm{minute}$ where: $A=($ hexane with $0.1 \%$ diethylamine) and $B=(9: 1$ chloroform-methanol with $0.1 \%$ diethylamine). Fractions corresponding to $42 \sim 47$ minutes were combined, and the solvent was removed in vacuo. Three separate injections yielded a total of $47 \mathrm{mg}$.

This material was further purified by reverse phase HPLC using a Phenomenex $5 \mu \mathrm{m}$ hexyl-phenyl column $(21.2 \times 250 \mathrm{~mm})$ with a mobile phase gradient of A-B $70: 30$ to $65: 35$ over 100 minutes at $20 \mathrm{ml} /$ minute where: $A=(0.05 \mathrm{M}$ aqueous ammonium acetate with $0.1 \%$ TFA $)$ and $\mathrm{B}=$ (acetonitrile - tetrahydrofuran $4: 1$ ). Fractions corresponding to $42 \sim 57$ minutes were combined and saturated with sodium bicarbonate. The product was extracted with dichloromethane and dried in vacuo. Two separate injections yielded a total of $19 \mathrm{mg}$. This material was further purified by reverse phase HPLC using a $5 \mu \mathrm{m}$ Phenomenex C8 Luna column $(21.2 \times 250 \mathrm{~mm})$ with a mobile phase gradient consisting of $(0.05 \mathrm{M}$ aqueous ammonium acetate with $0.1 \%$ TFA)-methanol $40: 60$ to $35: 65$ over 50 minutes at $20 \mathrm{ml} /$ minute. Fractions corresponding to $20 \sim 25$ minutes
Fig. 2. Proposed structure and fragmentation for 6-deoxy-13-cyclopropyl-erythromycin B (4).

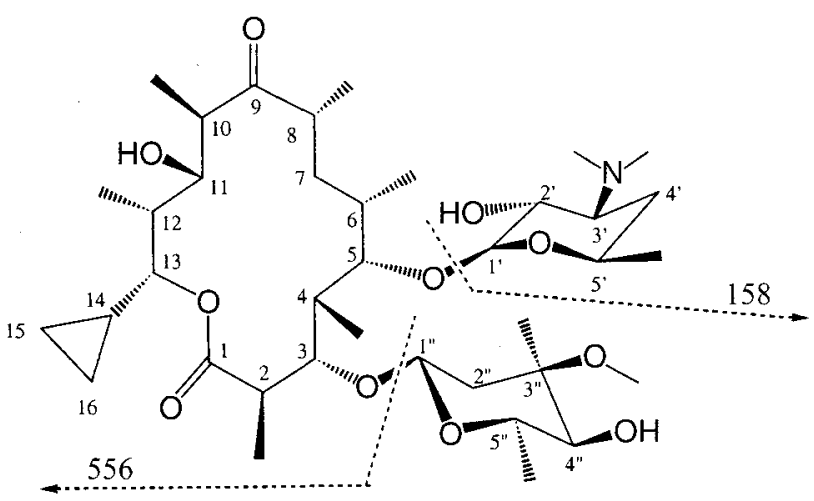

were combined and saturated with sodium bicarbonate. The product was extracted with dichloromethane and dried in vacuo yielding $11 \mathrm{mg}$ purified material.

\section{Analysis}

HPLC-MS data was acquired using a Hewlett-Packard 1050 liquid chromatograph interfaced to a VG Platform II mass spectrometer equipped with an APcI source. The following chromatographic conditions were used: Waters Symmetry $5 \mu \mathrm{m} \mathrm{C18:} 2.1 \times 150 \mathrm{~mm}$ HPLC column with a mobile phase gradient of $10 \mathrm{~mm}$ ammonium acetate-acetonitrile $70: 30$ to $50: 50$ in 30 minutes, at a flow rate of $0.22 \mathrm{ml} /$ minute, $6 \mu \mathrm{l}$ injection volume.

The following NMR experiments were acquired on a Bruker DMX500 using a $5 \mathrm{~mm}$ z-gradient inverse broadband probe: proton, carbon, DEPT, gradient COSY, gradient HMQC (Heteronuclear Multiple Quantum Correlation spectroscopy), and gradient HMBC (Heteronuclear Multiple Bond Correlation spectroscopy). HR-MS data supporting molecular formula assignments were obtained through M-Scan, Inc., West Chester, PA, using a VG Analytical AutoSpec E spectrometer operated with an LSIMS $\left(\mathrm{Cs}^{+}\right.$ion bombardment) ion source.

Mean Minimum Inhibitory Concentration Assays

MIC's (run in triplicate) were determined according to NCCLS standard methodology. 
Table 1. NMR assignment for 4.

(All ppm values are relative to TMS)

\begin{tabular}{cccc|cccc}
\hline Atom & ${ }^{13} \mathrm{C}-\mathrm{ppm}$ & \# of attached $\mathrm{H}$ & ${ }^{1} \mathrm{H}-\mathrm{ppm}$ & Atom & ${ }^{13} \mathrm{C}-\mathrm{ppm}$ & \# of attached $\mathrm{H}$ & ${ }^{1} \mathrm{H}-\mathrm{ppm}$ \\
\hline 1 & 177.5 & 0 & & $8 \mathrm{Me}$ & 17.16 & 3 & 1.2 \\
2 & 45.39 & 1 & 2.94 & $10 \mathrm{Me}$ & 8.33 & 3 & 1.09 \\
3 & 80.51 & 1 & 3.66 & $12 \mathrm{Me}$ & 10.15 & 3 & 1.04 \\
4 & 43.56 & 1 & 1.77 & 1 & 103.94 & 1 & 4.36 \\
5 & 85.74 & 1 & 3.52 & 2 & 70.4 & 1 & 3.55 \\
6 & 37.2 & 1 & 1.58 & 3 & 66.38 & 1 & 3.37 \\
7 & 34.78 & 2 & $1.82 / 1.26$ & 4 & 31.47 & 2 & $2.03 / 1.51$ \\
8 & 45.39 & 1 & 2.64 & 5 & 68.22 & 1 & 3.62 \\
9 & 217.38 & 0 & & 3 'NMe $(2)$ & 40.23 & 3 & 2.86 \\
10 & 42 & 1 & 2.92 & $5 ' \mathrm{Me}$ & 21.32 & 3 & 1.34 \\
11 & 70.53 & 1 & 3.52 & $1 "$ & 97.96 & 1 & 4.88 \\
12 & 41.86 & 1 & 1.93 & $2 "$ & 35.59 & 2 & $2.40 / 1.60$ \\
13 & 79.97 & 1 & 4.52 & $3 "$ & 73.02 & 0 & \\
14 & 13.53 & 1 & 1.22 & $4 "$ & 78.35 & 1 & 3.06 \\
15 & 4.82 & 2 & $0.63 / 0.44$ & $5 "$ & 66.09 & 1 & 3.97 \\
16 & 3.44 & 2 & $0.63 / 0.33$ & $3 " \mathrm{Me}$ & 49.71 & 3 & 3.31 \\
$2 \mathrm{Me}$ & 15.5 & 3 & 1.26 & $3^{\prime \prime} \mathrm{OMe}$ & 21.83 & 3 & 1.28 \\
$4 \mathrm{Me}$ & 10.2 & 3 & 1.2 & $5 " \mathrm{Me}$ & 18.55 & 3 & 1.32 \\
$6 \mathrm{Me}$ & 20.17 & 3 & 1.25 & & & & \\
\hline
\end{tabular}

Table 2. Mean minimum inhibitory concentration in $\mu \mathrm{g} / \mathrm{ml}$ (run in triplicate).

\begin{tabular}{|c|c|c|c|c|}
\hline Organism & $\begin{array}{c}\text { Erythromycin } \\
\text { B (2) }\end{array}$ & $\begin{array}{c}\text { Erythromycin } \\
\mathrm{A}(\mathbf{3}) \\
\end{array}$ & $\begin{array}{l}\text { 6-Deoxy- } \\
\text { erythromycin A }\end{array}$ & $\begin{array}{c}\text { 6-Deoxy-13- } \\
\text { cyclopropyl- } \\
\text { erythromycin B (4) }\end{array}$ \\
\hline Staphylococcus aureus 1116 & $\leqq 0.2$ & $\leqq 0.2$ & 1.56 & 1.56 \\
\hline Staphylococcus aureus $1117^{\mathrm{a}}$ & $>100$ & $>100$ & $>100$ & $>100$ \\
\hline Staphylococcus aureus 0052 & $\leqq 0.2$ & $\leqq 0.2$ & 0.39 & 0.78 \\
\hline Staphylococcus aureus $1120^{\mathrm{a}}$ & $>100$ & $>100$ & $>100$ & $>100$ \\
\hline Staphylococcus aureus $0129^{\mathrm{a}}$ & $>100$ & $>100$ & $>100$ & $>100$ \\
\hline Staphylococcus aureus $1032^{\mathrm{a}}$ & 100 & 100 & 50 & 100 \\
\hline Streptococcus hemolyticus 1006 & 100 & $>100$ & 100 & 100 \\
\hline Streptococcus agalactiae $1023^{\mathrm{a}}$ & $>100$ & $>100$ & $>100$ & $>100$ \\
\hline Streptococcus agalactiae 1024 & $\leqq 0.2$ & $\leq 0.2$ & $\leqq 0.2$ & $\leqq 0.2$ \\
\hline Streptococcus pyogenes 0203 & $\leqq 0.125$ & $\leqq 0.125$ & $\leqq 0.125$ & $\leqq 0.125$ \\
\hline Streptococcus pyogenes 1079 & $>64$ & $>64$ & $>64$ & $>64$ \\
\hline Streptococcus pyogenes 1064 & 8 & 8 & 16 & 8 \\
\hline $\begin{array}{l}\text { Streptococcus pyogenes } 1064 \\
+ \text { Eryc }^{c}\end{array}$ & 8 & 16 & 16 & 8 \\
\hline Streptococcus pneumoniae 1016 & 0.0625 & 0.0312 & 0.125 & 0.5 \\
\hline Streptococcus pneumoniae 1046 & $>100$ & $>100$ & $>10$ & $>100$ \\
\hline Streptococcus pneumoniae 1095 & $>10$ & $>10$ & $>10$ & $>10$ \\
\hline Streptococcus pneumoniae 1175 & $>10$ & $>10$ & $>10$ & $>10$ \\
\hline $\begin{array}{l}\text { Streptococcus pneumoniae } 1175 \\
+ \text { Eryc }^{c}\end{array}$ & 10 & $>10$ & $>10$ & $>10$ \\
\hline Haemophilus influenzae 1100 & 0.2 & 2 & not tested & 32 \\
\hline Haemophilus influenzae $0131^{\mathrm{b}}$ & 4 & 4 & 32 & 32 \\
\hline Moraxella catarrhalis 0040 & $\leqq 0.125$ & $\leqq 0.125$ & $\leqq 0.125$ & 0.25 \\
\hline Moraxella catarrhalis 1055 & 2 & 2 & 4 & 8 \\
\hline Escherichia coli 0266 & 100 & 100 & $>100$ & $>100$ \\
\hline
\end{tabular}

${ }^{a}$ : Multiply resistant strains generated at Pfizer or hospital isolates. ${ }^{b}$ : Hospital isolate. ${ }^{c}$ : Resistance induced by adding erythromycin. 
Fig. 3. Mass spectral data for 4.

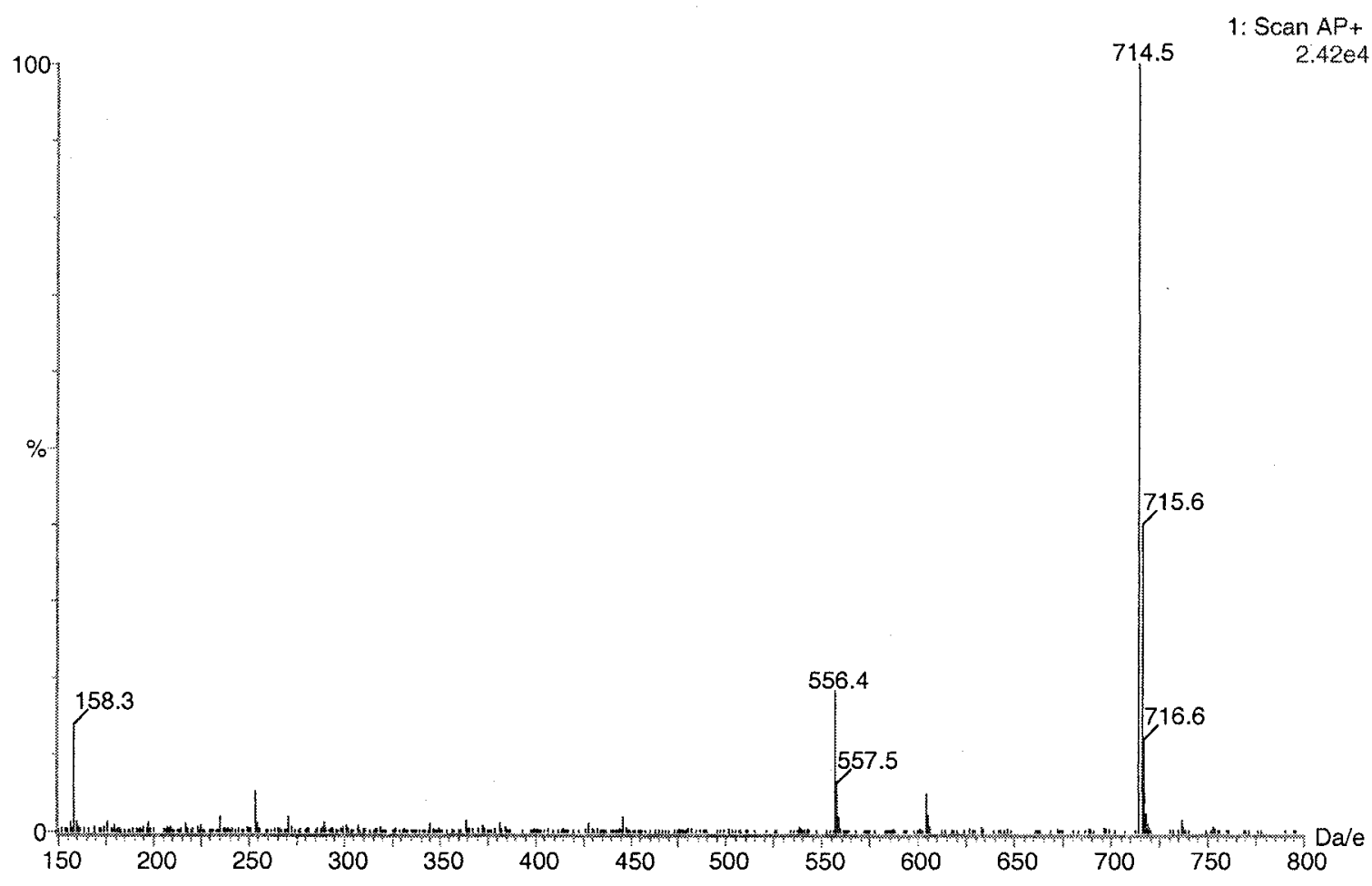

\section{Results and Discussion}

\section{Structure Elucidation}

The isolated material was characterized as 6-deoxy-13cyclopropyl-erythromycin B (4, Figure 2) by mass spectroscopy and NMR spectroscopy (Table 1). The mass spectrum (Figure 3) contained a base peak of $m / z$ 714.5, consistent with the proposed structure 4 . In addition, the peak at $m / z 556.4$ is consistent with the loss of the neutral sugar cladinose, a common fragment in the erythromycin series. Also consistent with the proposed structure is the signal at $m / z 158.3$ which is characteristic of the basic sugar desosamine. High resolution $\mathrm{MS}\left(\mathrm{M}+\mathrm{H}^{+}=714.4748\right)$ was consistent with the formula $\mathrm{C}_{38} \mathrm{H}_{67} \mathrm{NO}_{11}$ to within $6 \mathrm{ppm}$.

2D NMR determined the line assignment described in Table 1. The number of observed carbons, the respective number of attached protons and the inferred number of oxygen, nitrogen and hydroxyl groups give rise to a calculated molecular formula of $\mathrm{C}_{38} \mathrm{H}_{67} \mathrm{NO}_{11}$ with a total mass consistent with the mass spectral data ${ }^{8)}$. The two most pertinent assignments, i.e., the presence of a cyclopropyl group at the 13 position, and the absence of the hydroxyl group at the 6 position, are described in detail below.
The methylene proton and carbon chemical shifts of a cyclopropyl group are quite unique, both being much more up field when compared to other cyclic hydrocarbons. The observed chemical shift values of 3.44 and $4.83 \mathrm{ppm}$ in the carbon spectra and their corresponding proton shifts of $0.33 / 0.63 \mathrm{ppm}$ and $0.44 / 0.63 \mathrm{ppm}$ in the proton spectra for the methylenes (positions 16 and 15 , respectively) are easily identified in the gr-HMQC spectrum and are consistent with the presence of a cyclopropyl group. The gr-COSY correlates the methylenes to the cyclopropyl methine at position $14(1.22 \mathrm{ppm})$, which in turn shows a correlation to the methine proton $(4.52 \mathrm{ppm})$ at position 13 of the macrolide ring, indicating that the cyclopropyl moiety is attached to the ring at this position. In addition, the grHMBC data identifies the position of attachment as being two bonds away from the carboxy carbon at position 1 and adjacent to an oxygen as determined by carbon chemical shift (79.97 ppm).

An extensive spin system was observed in the gr-COSY spectrum consisting of six methines, one methylene, and four methyls [2(2-Me), 3(O), 4(4-Me), 5(O), 6(6-Me), 7, $8(8-\mathrm{Me})]$. Gr-HMBC correlations from positions $l^{\prime}$ and $1^{\prime \prime}$ to methines in this spin system and from the carbon at position 1 to the 2-Me protons led to the assignments listed in 
Table 1. In this spin system the only carbons adjacent to oxygen (as determined by chemical shift) are those at the point of attachment of the two sugars, indicating that the hydroxyl group is not present at position 6 . Consistent with this assignment, the chemical shifts of the C6 carbon $(37.20$ $\mathrm{ppm})$ and the $\mathrm{C} 6$ hydrogen $(1.58 \mathrm{ppm})$ indicate that there is no hydroxyl group attached at this position.

\section{Antibacterial Activity}

Antibacterial activity (MIC) of 4 was compared to structurally similar erythromycins. Results of these assays are shown in Table 2.

\section{Discussion}

The incorporation of cyclopropane carboxylic acid to form 6-deoxy-13-cyclopropyl-erythromycin B (4) provides another example of the relaxed specificity of the DEBS starter unit in vivo. Previously, the loading domain of the wild type erythromycin producer has been shown to accept acetate to form low levels of 15-nor-erythromycin $\mathrm{C}^{3)}$. Similar results were seen when DEBS was expressed in Streptomyces coelicolor ${ }^{9}$. These results are not surprising given the similarity to the propionate-derived erythromycin starter unit. The incorporation of a larger starter unit, butyryl CoA, to produce a novel triketide lactone has only been shown in an in vitro system ${ }^{2)}$. The formation of the novel 6-deoxy-erythromycin $\mathrm{B}$ derivative reported herein clearly demonstrates that the DEBS loading domain is relaxed with respect to larger starting units in vivo as well.

The novel macrolide had biological activity (Table 2) similar to 6-deoxy-erythromycin A, but was less effective than erythromycins $\mathrm{A}$ and $\mathrm{B}$ against some pathogens. 6deoxy-13-cyclopropyl-erythromycin B was less active than erythromycins A and B against Staphylococcus aureus 1116, Staphylococcus aureus 0052, Streptococcus pneumoniae 1016, Streptococcus pneumoniae 1175, Haemophilus infuenzae 1100, Haemophilus infuenza 0131, Moraxella catarrhalis 0040, and Moraxella catarrhalis 1055. This dif- ference may be attributed to the lack of the C- 6 hydroxyl group, rather than the novel C-13 cyclopropyl group.

\section{Acknowledgments}

We would like to acknowledge JoYCE SUTCLIFFE, JOAN DUIGNAN and LORI BRENNAN for MIC data (all at Pfizer Central Research, Groton, CT)

\section{References}

1) Marsden, A. F. A.; P. Caffrey, J. F. Aparicio, M. S. Loughran, J. Staunton \& P. F. Leadlay: Stereospecific acyl transfers on the erythromycin-producing polyketide synthase. Science 263: 378 380, 1994

2) PIePer, R.; G. Luo, D. E. Cane \& C. Khosla: Remarkably broad substrate specificity of a modular polyketide synthase in a cell-free system. J. Am. Chem. Soc. 117: 11373 74, 1995

3) Kibwage, I. O.; G. Janssen, R. Busson, J. Hoogmartens $\&$ H. Vanderhaeghe: Identification of novel erythromycin derivatives in mother liquor concentrates of Streptomyces erythraeus. J. Antibiotics 40: 1 6, 1986

4) Martin, J. R,; R. S. Egan, A. W. Goldstein, S. L. Mueller, E. A. Hirner \& R. S. Stanaszek: 8,8A-Deoxyoleandolide: Elaborated by a blocked mutant of the erythromycin-producing organism Streptomyces erythraeus. J. Antibiotics 27: 570 572, 1974

5) Pacey, M. S.; J, P. Dirlam, R. W. Geldart, P. F. LeadLAY, H. A. I. MCARTHUR, E. L. MCCORMICK, R. A. MONDAY, T. N. O'CONNELL, J. STAUNTON \& T. J. WinCHESTER: Novel erythromycins from a recombinant saccharopolyspora strain NRRL 2338pIG1. 1. Fermentation, isolation and biological activity. J. Antibiotics 51: $1029 \sim 1034,1998$

6) Weber, J. M.; J. O. Leung, S. J. Swanson, K. B. Idler \& J. B. MCALPINE: An erythromycin derivative produced by targeted gene disruption in Saccharopolyspora erythraea. Science 252: 114 117, 1991

7) Donadio, S.; M. J. Staver, J. B. Mcalpine, S. J. SwanSON \& L. KATZ: Modular organization of genes required for complex polyketide biosynthesis. Science 252: $675 \sim 679,1991$

8) Bordner, J.; P. C. Watts \& E. B. WhipPle: Structure of the natural antibiotic ionophore CP-54,883. J. Antibiotics 40: $1496 \sim 1505,1987$

9) KaO, C. M.; L. Katz \& C. Khosla: Engineered biosynthesis of a complete macrolactone in a heterologous host. Science 265: 509 -512, 1994 